\title{
Sequence polymorphisms of the mitochondrial displacement loop and outcome of non-small cell lung cancer
}

\author{
CUIMIN DING $^{1}$, RUIJUAN LI ${ }^{1}$, PING WANG ${ }^{1}$, HAIYAN FAN ${ }^{2}$ and ZHANJUN GUO ${ }^{2}$ \\ Departments of ${ }^{1}$ Respiratory Medicine, and ${ }^{2}$ Gastroenterology and Hepatology, The Fourth Hospital of \\ Hebei Medical University, Shijiazhuang, Hebei 050011, P.R. China \\ Received December 7, 2011; Accepted February 10, 2012
}

DOI: $10.3892 / \mathrm{etm} .2012 .490$

\begin{abstract}
Accumulation of single-nucleotide polymorphisms (SNPs) in the displacement loop (D-loop) of mitochondrial DNA (mtDNA) may be associated with disease outcome. Our team investigated the prediction power of D-loop SNPs in non-small cell lung cancer (NSCLC) outcome. In an overall multivariate analysis, allele 16390 was identified as an independent predictor for NSCLC outcome. The length of survival of patients with allele 16390A was significantly shorter than that of patients with allele $16390 \mathrm{G}$ (relative risk, 0.323 ; 95\% CI, $0.109-0.951 ; \mathrm{p}=0.040)$. The analysis of genetic polymorphisms in the mitochondrial D-loop can help identify NSCLC patient subgroups at a high risk for a poor disease outcome.
\end{abstract}

\section{Introduction}

Lung cancer is the most frequent cancer and one of the leading causes of cancer-related deaths worldwide, accounting for $30 \%$ of all cancer-related deaths. An epidemiological study estimated that the number of deaths due to lung cancer in 2010 was 1.5 million, rendering lung cancer a major public health challenge $(1,2)$. The annual mortality rate of lung cancer in China is high with approximately 400 thousand deaths (3). Non-small cell lung cancer (NSCLC) accounts for $89 \%$ of all lung cancers and approximately one third of NSCLC patients are diagnosed at a locally advanced stage $(4,5)$. Despite aggressive treatment, the prognosis of NSCLC patients is still poor with a 5-year survival rate of approximately $10 \%$ and a median survival time of 16-18 months (6,7). Many clinical factors, such as tumor stage, metastasis, gender and weight loss, are predictors of prognosis of NSCLC patients (8), but there are few studies concerning the relationship between oxidative markers and NSCLC prognosis (9).

Correspondence to: Dr Zhanjun Guo, Department of Gastroenterology and Hepatology, The Fourth Hospital of Hebei Medical University, 12 Jiankang Road, Shijiazhuang, Hebei 050011, P.R. China

E-mail: zjguo5886@yahoo.com.cn

Key words: displacement loop, non-small cell lung cancer, outcome, single-nucleotide polymorphism, mitochondrial DNA
Lung cancer carcinogenesis is associated with increased oxidative stress which results in DNA damage $(10,11)$. The human mitochondrial genome is a 16-kb closed-circular duplex molecule that contains 37 genes, including two ribosomal RNAs and a complete set of 22 tRNAs (12). Mitochondrial DNA (mtDNA) is believed to be more susceptible to DNA damage and acquires mutations at a higher rate than nuclear DNA because of high levels of reactive oxygen species (ROS), lack of protective histones and the limited capacity for DNA repair in mitochondria (13-15). Somatic mtDNA mutations and polymorphisms are associated with a wide variety of degenerative diseases and cancers $(16,17)$, and can be homoplasmic by clonal expansion $(18,19)$, or heteroplasmic in tumor tissues $(20,21)$. In many cancers, somatic mutations and polymorphisms are located in an mtDNA non-coding region called the displacement loop (D-loop) $(22,23)$, which contains $1122 \mathrm{bp}$ (nucleotides 16024-16569 and 1-576; www.mitomap.org). This region is important for the regulation of both replication and expression of the mitochondrial genome as it contains the leading-strand origin of replication and the main promoter for transcription (24).

Sequence changes have been examined extensively in the D-loop in cancers, but few single-nucleotide polymorphisms (SNPs) have been selected for predicting cancer risk and outcome; their predictive values are still unclear (25-29). In this study, we assessed the prediction power of these SNPs on the outcome of NSCLC patients.

\section{Materials and methods}

Tissue specimens and DNA extraction. Blood samples were collected at The Fourth Hospital of Hebei University from NSCLC patients who received treatment at the Department of Respiratory Medicine between 2001 and 2009. The genomic DNA was immediately extracted using the Wizard Genomic DNA extraction kit (Promega, Madison, WI, USA) and stored at $-20^{\circ} \mathrm{C}$. All procedures were supervised and approved by the Human Tissue Research Committee of our hospital, and an informed consent was obtained from all participants.

PCR amplification and sequence analysis. The forward primer, 5'-CCCCATGCTTACAAGCAAGT-3' (nucleotide 16190-16209) and reverse, 5'-GCTTTGAGGAGGTAAGC TAC-3' (nucleotide 602-583) were used for amplification of a 
Table I. Univariate analysis of clinical characteristics associated with overall survival in the NSCLC patients.

\begin{tabular}{lccc}
\hline Characteristics & No. of cases & $\begin{array}{c}\text { 2-year survival } \\
\text { rate }(\%)\end{array}$ & p-value \\
\hline Gender & & & 0.382 \\
$\quad$ Male & 48 & 67.1 & \\
Female & 28 & 28.6 & 0.715 \\
Age (years) & & 26.1 & \\
$\leq 45$ & 7 & & \\
$>45$ & 69 & 25.0 & 0.520 \\
TNM & & 26.8 & \\
classification & & & 0.253 \\
III & 20 & 19.4 & \\
IV & 56 & 32.5 & \\
Smoking & & & 0.000 \\
Yes & 36 & 29.9 & \\
No & 40 & 0 & 0.669 \\
Treatment & & & \\
Yes & 67 & 28.0 & \\
No & 9 & 25.5 & \\
Histology & & 25 & \\
SQ & 51 & & \\
AC & &
\end{tabular}

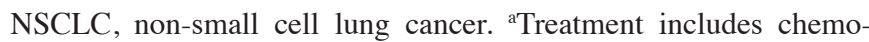
therapy, radiotherapy, and chemotherapy plus radiotherapy. $\mathrm{SQ}$, squamous cell carcinoma; AC, adenocarcinoma.

982-bp product from the mtDNA D-loop region. PCR was performed according to the protocol included in the PCR Master Mix kit (Promega) and purified prior to sequencing. Cycle sequencing was carried out with the Dye Terminator Cycle Sequencing Ready Reaction kit (Applied Biosystems, Foster City, CA, USA) and the products were then separated on the ABI PRISM Genetic Analyzer 3100 (Applied Biosystems). Polymorphisms were confirmed by repeated analyses from both strands.

Statistical analysis. Survival curves were calculated using the Kaplan-Meier method, and compared with the log-rank test. Multivariate survival analysis was performed using a Cox proportional hazards model. All of the statistical analysis was carried out with the SPSS 13.0 software package (SPSS Co., Chicago, IL, USA). $\mathrm{P}<0.05$ was considered to indicate a statistically significant difference.

\section{Results}

A total of 80 patients were enrolled in this study and a followup review was conducted every 3 months for 2 years. One patient was lost to follow-up at the first year and 3 patients were lost at the second year. The remaining 76 patients shared the same performance status (ECOG score, 0). Of these, 20 patients were at stage III, 56 at stage IV and 56 died during follow-up. The data collected during the 2-year follow-up were
A

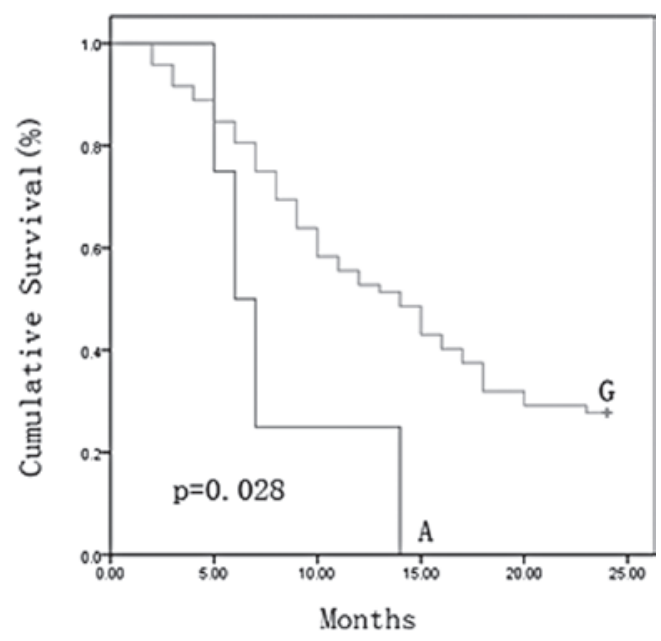

B

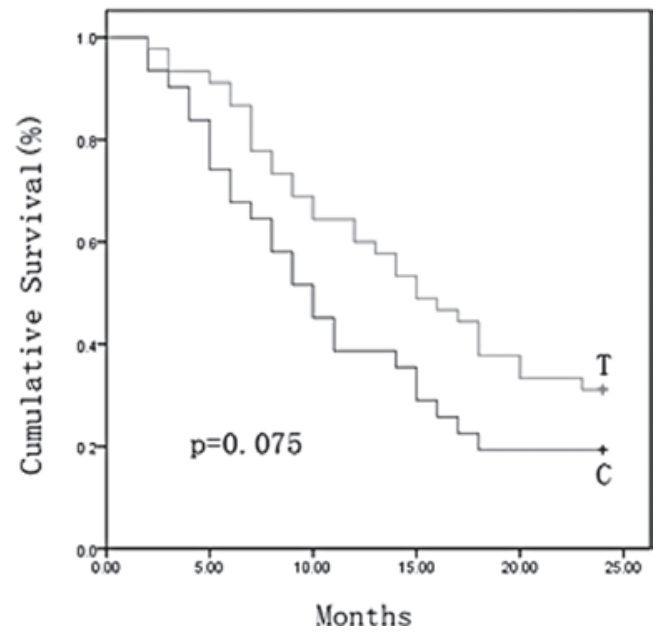

Figure 1. Survival curves according to the nucleotide at position (A) 16390 and (B) 16519 in the displacement loop (D-loop) of NSCLC patients.

analyzed for clinical characteristics using the Kaplan-Meier method and were compared by the log-rank test. Gender, age, TNM classification, smoking and histology were not statistically significant predictors of the length of overall survival, however treatment was correlated with survival in these patients (Table I).

We sequenced the D-loop region in all of the 76 NSCLC patients and 121 SNPs were identified. The relationship between survival and the 121 SNPs was examined. The NSCLC patients were divided into two groups on the basis of their genotype at each SNP site, and overall survival curve was plotted using the Kaplan-Meier method for all NSCLC patients at these sites. A dramatic difference in survival rate was found for nucleotide $16390(\mathrm{p}=0.028)$ and another nucleotide of 16519 was also identified with borderline level of difference $(\mathrm{p}=0.075)$. The minor allele $16390 \mathrm{~A}$ and $16519 \mathrm{C}$ were associated with a shorter length of survival (Fig. 1A and B). We performed multivariate analysis for these predictors including these two SNPs and treatment with the Cox proportional hazards model. As shown in Table II, the 16390 alleles and treatment were identified as independent predictors for NSCLC outcome. The length of survival for patients with the minor allele 16390A genotype was significantly less than that for patients with the common allele $16390 \mathrm{G}$ (relative risk, 0.323; 
Table II. Multivariate analysis of prognostic factors associated with overall survival in NSCLC patients with Cox proportional hazards model.

\begin{tabular}{lccc}
\hline Factors & Relative risk & $95 \%$ CI & p-value \\
\hline $\begin{array}{l}\text { Treatment } \\
\text { Nucleotide }\end{array}$ & 0.143 & $0.065-0.315$ & 0.000 \\
16390 & 0.323 & $0.109-0.951$ & 0.040 \\
16519 & 0.628 & $0.361-1.093$ & 0.100 \\
\hline
\end{tabular}

NSCLC, non-small cell lung cancer.

95\% CI, 0.109-0.951; $\mathrm{p}=0.040)$ at the 16390 site. These data demonstrated the strong prediction power of nucleotide 16390 on outcome for NSCLC patients.

\section{Discussion}

We previously identified cancer risk and outcome-associated SNPs of the D-loop in several types of cancer $(25,26,30)$. In this study, selected SNPs in the mtDNA D-loop were examined for their ability to predict cancer outcome in NSCLC patients. Two SNPs, 16390 (G/A) and 16519 (T/C), were identified by the log-rank test for their association with overall survival. Multivariate survival analysis identified 16390 (G/A) as independent prediction markers for NSCLC outcome.

The mtDNA D-loop is important for regulation of mitochondrial genome replication and expression. SNPs in this region may affect mtDNA replication so as to alter the electron transport chain, which is responsible for the high ROS release and nuclear genome damage as well as cancer initiation and promotion (31-33). Overexpression of protein binding to the D-loop region has been proven to increase ROS and affect tumor progression (34).

In conclusion, SNPs in the mtDNA D-loop were found to be independent prognostic markers for NSCLC outcome. The analysis of genetic polymorphisms in the D-loop may help to identify patient subgroups at a high risk for poor disease outcome, thereby helping to refine therapeutic decisions in NSCLC.

\section{Acknowledgements}

This study was supported by the National Natural Science Foundation of China (no. 30801384).

\section{References}

1. Parkin DM, Bray FI and Devesa SS: Cancer burden in the year 2000. The global picture. Eur J Cancer 37 (Suppl 8): S4-S66, 2001.

2. Cao C, Zhang YM, Wang R, Sun SF, Chen ZB, Ma HY, Yu YM, Ding QL, Shu LH and Deng ZC: Excision repair cross complementation group 1 polymorphisms and lung cancer risk: a meta-analysis. Chin Med J (Engl) 124: 2203-2208, 2011.

3. Yang L, Yang G, Zhou M, Smith M, Ge H, Boreham J, Hu Y, Peto R, Wang J and Chen Z: Body mass index and mortality from lung cancer in smokers and nonsmokers: a nationally representative prospective study of 220,000 men in China. Int J Cancer 125: 2136-2143, 2009.
4. Gandara D, Narayan S, Lara PN Jr, Goldberg Z, Davies A, Lau DH, Mack P, Gumerlock P and Vijayakumar S: Integration of novel therapeutics into combined modality therapy of locally advanced non-small cell lung cancer. Clin Cancer Res 11: 5057s-5062s, 2005.

5. Yin M, Liao Z, Huang YJ, Liu Z, Yuan X, Gomez D, Wang LE and Wei Q: Polymorphisms of homologous recombination genes and clinical outcomes of non-small cell lung cancer patients treated with definitive radiotherapy. PLoS One 6: e20055, 2011.

6. Yang P, Allen MS, Aubry MC, Wampfler JA, Marks RS, Edell ES, Thibodeau S, Adjei AA, Jett J and Deschamps C: Clinical features of 5,628 primary lung cancer patients: experience at Mayo Clinic from 1997 to 2003. Chest 128: 452-462, 2005.

7. Cullen MH, Billingham LJ, Woodroffe CM, Chetiyawardana AD, Gower NH, Joshi R, Ferry DR, Rudd RM, Spiro SG, Cook JE, et al: Mitomycin, ifosfamide, and cisplatin in unresectable non-small-cell lung cancer: effects on survival and quality of life. J Clin Oncol 17: 3188-3194, 1999.

8. Bi N, Yang M, Zhang L, Chen X, Ji W, Ou G, Lin D and Wang L: Cyclooxygenase-2 genetic variants are associated with survival in unresectable locally advanced non-small cell lung cancer. Clin Cancer Res 16: 2383-2390, 2010.

9. Gupta A, Srivastava S, Prasad R, Natu SM, Mittal B, Negi MP and Srivastava AN: Oxidative stress in non-small cell lung cancer patients after chemotherapy: association with treatment response. Respirology 15: 349-356, 2010.

10. Loft S, Svoboda P, Kawai K, Kasai H, Sørensen M, Tjønneland A Vogel U, Møller P, Overvad K and Raaschou-Nielsen O: Association between 8-oxo-7,8-dihydroguanine excretion and risk of lung cancer in a prospective study. Free Radic Biol Med: Oct. 20, 2011 (E-pub ahead of print).

11. Lawless MW, O'Byrne KJ and Gray SG: Oxidative stress induced lung cancer and COPD: opportunities for epigenetic therapy. J Cell Mol Med 13: 2800-2821, 2009.

12. Shadel GS and Clayton DA: Mitochondrial DNA maintenance in vertebrates. Annu Rev Biochem 66: 409-435, 1997.

13. DiMauro S and Schon EA: Mitochondrial DNA mutations in human disease. Am J Med Genet 106: 18-26, 2001.

14. Beal MF: Mitochondia, free radicals, and neurodegeneration. Curr Opin Neurobiol 6: 661-666, 1996.

15. Lightowlers RN, Chinnery PF, Turnbull DM, and Howell N: Mammalian mitochondrial genetics: heredity, heteroplasmy and disease. Trends Genet 13: 450-455, 1997.

16. Wallace DC: Mouse models for mitochondrial disease. Am J Med Genet 106: 71-93, 2001.

17. Fliss MS, Usadel H, Caballero OL, Wu L, Buta MR, Eleff SM, Jen J and Sidransky D: Facile detection of mitochondrial DNA mutations in tumors and bodily fluids. Science 287: 2017-2019, 2000.

18. Nomoto S, Yamashita K, Koshikawa K, Nakao A and Sidransky D: Mitochondrial D-loop mutation as clonal markers in multicentric hepatocellular carcimona and plasma. Clin Cancer Res 8: 481-487, 2002.

19. Mambo E, Gao X, Cohen Y, Guo Z, Talalay P and Sidransky D: Electrophile and oxidant damage of mitochondrial DNA leading to rapid evolution of homoplasmic mutations. Proc Natl Acad Sci USA 100: 1838-1843, 2003.

20. Yoneyama H, Hara T, Kato Y, Yamori T, Matsuura ET and Koike K: Nucleotide sequence variation is frequent in the mitochondrial DNA displacement loop region of individual human tumor cells. Mol Cancer Res 3: 14-20, 2005.

21. Jakupciak JP, Maragh S, Markowitz ME, Greenberg AK, Hoque MO, Maitra A, Barker PE, Wagner PD, Rom WN, Srivastava S, Sidransky D and O'Connell CD: Performance of mitochondrial DNA mutations detecting early stage cancer. BMC Cancer 8: 285, 2008.

22. Nashikawa M, Nishiguchi S, Shiomi S, Tamori A, Koh N, Takeda T, Kubo S, Hirohashi K, Kinoshita H, Sato E and Inoue M: Somatic mutation of mitochondrial DNA in cancerous and noncancerous liver tissue in individuals with hepatocellular carcinoma. Cancer Res 61: 1843-1845, 2001.

23. Sanchez-Cespedes M, Parrella P, Nomoto S, Cohen D, Xiao Y, Esteller M, Jeronimo C, Jordan RC, Nicol T and Koch WM: Identification of a mononucleotide repeat as a major target for mitochondrial DNA alterations in human tumors. Cancer Res 61: 7015-7019, 2001.

24. Taanman JW: The mitochondrial genome: structure, transcription, translation and replication. Biochim Biophys Acta 1410: 103-123, 1999. 
25. Zhang R, Zhang F, Wang C, Wang S, Shiao YH and Guo Z: Identification of sequence polymorphism in the $\mathrm{D}$-loop region of mitochondrial DNA as a risk factor for hepatocellular carcinoma with distinct etiology. J Exp Clin Cancer Res 29: 130, 2010.

26. Wang C, Zhang F, Fan H, Peng L, Zhang R, Liu S and Guo Z: Sequence polymorphisms of mitochondrial D-loop and hepatocellular carcinoma outcome. Biochem Biophys Res Commun 406: 493-496, 2011.

27. Navaglia F, Basso D, Fogar P, Sperti C, Greco E, Zambon CF Stranges A, Falda A, Pizzi S, Parenti A, Pedrazzoli S and Plebani M: Mitochondrial DNA D-loop in pancreatic cancer: somatic mutations are epiphenomena while the germline $16519 \mathrm{~T}$ variant worsens metabolism and outcome. Am J Clin Pathol 126 593-601, 2006

28. Wang L, Bamlet WR, de Andrade M, Boardman LA Cunningham JM, Thibodeau SN and Petersen GM: Mitochondrial genetic polymorphisms and pancreatic cancer risk. Cancer Epidemiol Biomarkers Prev 16: 1455-1459, 2007

29. Wang L, McDonnell SK, Hebbring SJ, Cunningham JM, St Sauver J, Cerhan JR, Isaya G, Schaid DJ and Thibodeau SN Polymorphisms in mitochondrial genes and prostate cancer risk. Cancer Epidemiol Biomarkers Prev 17: 3558-3566, 2008.
30. Zhang R, Wang R, Zhang F, Wu C, Fan H, Li Y, Wang C and Guo Z: Single-nucleotide polymorphisms in the mitochondrial displacement loop and outcome of esophageal squamous cell carcinoma. J Exp Clin Cancer Res 29: 155, 2010.

31. Bandy B and Davison AJ: Mitochondrial mutations may increase oxidative stress: implications for carcinogenesis and aging? Free Radic Biol Med 8: 523-539, 1990.

32. Gille JJ and Joenje H: Cell culture models for oxidative stress: superoxide and hydrogen peroxide versus normobaric hyperoxia. Mutat Res 275: 405-414, 1992.

33. Shigenaga MK, Hagen TM and Ames BN: Oxidative damage and mitochondrial decay in aging. Proc Natl Acad Sci USA 91: 10771-10778, 1994.

34. Dement GA, Maloney SC and Reeves R: Nuclear HMGA1 nonhistone chromatin proteins directly influence mitochondrial transcription, maintenance, and function. Exp Cell Res 313 77-87, 2007. 